SOUZA, Carlos Augusto da Silva; SILVA, Maria Dolores Lima da. Discursos divisionistas e criação de novos estados no Brasil: impactos no arranjo federativo. Revista Eletrônica Direito e Política, Programa de Pós-Graduação Stricto Sensu em Ciência Jurídica da UNIVALI, Itajaí, v.13, n.2, $2^{\circ}$ quadrimestre de 2018. Disponível em: www.univali.br/direitoepolitica - ISSN 1980-7791

\title{
DISCURSOS DIVISIONISTAS E CRIAÇÃO DE NOVOS ESTADOS NO BRASIL: IMPACTOS NO ARRANJO FEDERATIVO
}

\author{
THE DIVISIONISTS SPEECHES AND CREATION OF NEW STATES IN BRAZIL:
} IMPACTS ON FEDERATIVO ARRANGEMENT

\author{
Carlos Augusto da Silva Souza ${ }^{1}$ \\ Maria Dolores Lima da Silva²
}

SUMÁRIO: Introdução; 1 Aspectos históricos da redivisão territorial; 2 Os projetos de criação de novos estados no Brasil; 3 Os discursos Divisionistas; 3.1 O discurso da Extensão Territorial dos Estados e o Desenvolvimento Econômico; 3.20 discurso da segurança nacional e a redução dos impactos ambientais; 3.3. O Discurso da Diversidade Cultural; 3.4 O Discurso dos Interesses Políticos; 4 Conflitos federativos da redivisão territorial; Considerações Finais; Referência das fontes citadas.

\section{RESUMO}

O artigo apresenta como objetivo avaliar os discursos que alimentam a ideia da criação de novos estados no Brasil e os impactos da formação de novas unidades federativas na distribuição da representação política dos estados no Congresso Nacional. A pesquisa parte da evidência de que a criação de novos estados produzirá graves distorções no processo de representação territorial e comprometerá o ideal de equidade presente no pacto federativo. A metodologia utilizada consistiu em avaliar os argumentos que alimentam as propostas de criação de novos estados, confrontando as posições favoráveis com as posições contrárias, além de inserir indicadores que confrontam a representação atual com a representação futura, caso novas unidades sejam efetivamente criadas no país. Palavras Chaves: Criação de Novos Estados; Separatismo; Arranjo federativo.

\section{ABSTRACT}

The article presents how to evaluate the discourses that feed the idea of creation of new states in Brazil and the impacts that the formation of new federal units will result in the distribution of political representation of states in the National Congress. The research part of the evidences that the creation of new states will produce serious distortions in the process of territorial representation and undermine the ideal of equity present in the federative pact. The methodology

\footnotetext{
${ }^{1}$ Doutor em Ciência Política. Professor do Programa de Pós Graduação em Ciência Política na UFPA - Belém/Pará/Brasil. e-mail: carlossouza@ufpa.br

${ }^{2}$ Doutora em Ciência Política. Professora no Programa de Pós Graduação em Ciência Política na UFPA-Belém/Pará/Brasil. e-mail: mdls@ufpa.br
} 
SOUZA, Carlos Augusto da Silva; SILVA, Maria Dolores Lima da. Discursos divisionistas e criação de novos estados no Brasil: impactos no arranjo federativo. Revista Eletrônica Direito e Política, Programa de Pós-Graduação Stricto Sensu em Ciência Jurídica da UNIVALI, Itajaí, v.13, n.2, 20 quadrimestre de 2018. Disponível em: www.univali.br/direitoepolitica - ISSN 1980-7791

used was to assess the arguments that feed the proposed creation of new states, confronting the favorable positions with positions contrary, in addition to entering indicators that confront the current representation with the representation in the future, if new units are effectively created in the country.

Key Words: Creation of new states; separatism; federal arrangement.

\section{INTRODUÇÃO}

O Brasil, ao longo de seu desenvolvimento histórico, sempre conviveu com conflitos relativos à delimitação de fronteiras e à busca pela autonomia governativa de fragmentos de suas unidades administrativas. A partir da proclamação da República e da adoção do federalismo como forma de organização política do país, a proposta de criação de novos estados vem acompanhando o debate político, provocando tensões e calorosas discussões a respeito da criação de novas unidades administrativas.

De 1940 até os dias atuais, o país sofreu 17 alterações na configuração de suas unidades político-administrativas, através da criação de novas unidades federativas, fusão entre unidades e extinção de estados e territórios federais ${ }^{3}$. As últimas modificações ocorreram logo após a promulgação da Constituição Federal, em 1988, com a formação do estado do Tocantins, desmembrado do estado de Goiás, a elevação dos territórios do Amapá e Roraima à categoria de estado e a anexação do território federal de Fernando de Noronha ao estado de Pernambuco.

A partir de 1988 , com base nas regras constitucionais ${ }^{4}$ para criação de novas unidades federativas, diversas propostas de criação de estados passaram a tramitar no Congresso Nacional, mantendo esse tema na agenda política, o que tem mobilizado diversos setores da sociedade brasileira, favoráveis ou contrários à criação de novos estados no Brasil.

${ }^{3}$ LIMA, Maria Helena Palmer. Evolução da divisão político-administrativa brasileira de 1940 a 2007. Brasília: Instituto Brasileiro de Geografia e Estatística, 2011, p.147.

${ }^{4}$ As propostas de redivisão territorial se fundamentam $\S 3^{\circ}$ do artigo 18 da Constituição Federal do Brasil de 1988 que determina: "§ $3^{\circ}$ Os Estados podem incorporar-se entre si, subdividir-se ou desmembrar-se para se anexarem a outros, ou formarem novos Estados ou Territórios Federais, mediante aprovação da população diretamente interessada, através de plebiscito, e do Congresso Nacional, por lei complementar". 
SOUZA, Carlos Augusto da Silva; SILVA, Maria Dolores Lima da. Discursos divisionistas e criação de novos estados no Brasil: impactos no arranjo federativo. Revista Eletrônica Direito e Política, Programa de Pós-Graduação Stricto Sensu em Ciência Jurídica da UNIVALI, Itajaí, v.13, n.2, $2^{\circ}$ quadrimestre de 2018. Disponível em: www.univali.br/direitoepolitica - ISSN 1980-7791

Em 2011, o Congresso Nacional autorizou a realização de plebiscito para a criação de dois novos estados, Tapajós e Carajás, que deveriam ser desmembrados do atual estado do Pará. O plebiscito ocorreu no dia 11 de dezembro de 2011 com grande mobilização social, mas as duas propostas foram rejeitadas pela ampla maioria dos eleitores paraenses. Apesar do resultado desfavorável, os defensores da proposta de criação de novos estados continuam mobilizados para que seja autorizada a realização de plebiscitos para a criação de novas unidades federativas em diversas porções do território brasileiro.

Desde a promulgação da Constituição de 1988, diversas propostas para a criação de novos estados e territórios federais deram entrada no Congresso Nacional, mostrando que o tema continua na agenda política e constitui-se em um de problema de difícil solução, uma vez que envolve questões culturais, geopolíticas, econômicas, incluindo conflitos entre elites locais, acusações de interesses políticos pela criação de cargos e amplas divergências sobre como combater as desigualdades e trazer desenvolvimento a regiões com sérios déficits de desenvolvimento econômico e social. Nesse sentido, a proposta deste artigo consiste em avaliar, a partir de uma perspectiva política, os discursos, interesses e conflitos que a proposta de criação de novos estados trará para a representação política dos estados no arranjo federativo nacional.

A metodologia que orientou a discussão baseou-se nas justificativas das propostas de criação de novas unidades federativas que tramitaram no Congresso Nacional no período que vai de 1989 a 2011, contra argumentadas por alguns analistas que discutem a questão da redivisão territorial. Também foram mapeados alguns discursos presentes na campanha eleitoral realizada durante o plebiscito para a criação dos estados do Tapajós e Carajás, no estado do Pará.

A classificação do discurso foi realizada de forma intuitiva, de acordo com a posição defendida pelo argumento global presente nos documentos analisados (propostas de criação de novos estados, propaganda eleitoral das frentes do SIM e NÃO, durante a campanha eleitoral no plebiscito de criação dos estados do Tapajós e Carajás, e comentários presentes na literatura sobre o assunto). Posteriormente, utilizando os dados da representação atual na Câmara dos Deputados e da 
SOUZA, Carlos Augusto da Silva; SILVA, Maria Dolores Lima da. Discursos divisionistas e criação de novos estados no Brasil: impactos no arranjo federativo. Revista Eletrônica Direito e Política, Programa de Pós-Graduação Stricto Sensu em Ciência Jurídica da UNIVALI, Itajaí, v.13, n.2, 20 quadrimestre de 2018. Disponível em: www.univali.br/direitoepolitica - ISSN 1980-7791

representação hipotética, caso novos estados fossem criados, foi avaliado o impacto da redivisão territorial na representação política presente no Congresso Nacional, de acordo com a proporcionalidade da representação prevista na Constituição Federal.

\section{ASPECTOS HISTÓRICOS DA REDIVISÃO TERRITORIAL}

O tema da redivisão territorial no Brasil não é recente e vem acompanhando nossa trajetória histórica desde o descobrimento até os dias atuais. Em vários momentos de nossa história o desenho político-administrativo do território brasileiro foi alterado, seja através da criação de novas unidades administrativas quanto pela fusão ou extinção de unidades antigas. Os fatores que respondem pela alteração no mapa do país ao longo da história apresentam interesses e motivações diferenciadas, seja de natureza econômica, política, social ou cultural ${ }^{5}$.

Durante o processo de colonização, a primeira experiência de redivisão territorial ocorreu com a implantação das capitanias hereditárias. Esse sistema consistiu em dividir as terras portuguesas no Brasil em 15 faixas territoriais e doá-las a donatários com capacidade financeira para provocar um processo de povoamento de forma a garantir a efetiva soberania portuguesa sobre essa fração do continente americano. Com essa experiência, o governo português procurou contornar sua falta de recursos através de uma colonização pela via privada. O sistema de capitanias hereditárias durou até 1759 quando foram extintas e a maioria delas foi transformada em províncias, sob a direção de um governo geral.

No período compreendido entre 1580 e 1617, Portugal e Espanha passaram a compartilhar um único governo com a Unificação das Coroas Ibéricas. Nesse sentido, o território português passou a se expandir para a região amazônica, que, pelas determinações do tratado de Tordesilhas, constituía-se como possessão espanhola. Sob a orientação de Filipe III, através da Carta Régia de 04 de maio de 1617, a colônia portuguesa passou a se constituir de dois estados: estado do Brasil, com sede em Salvador, que incorporava as províncias derivadas do sistema

${ }^{5}$ ANDRADE, Manuel Correia de. As Raízes do Separatismo no Brasil. São Paulo: Fundação Editora da UNESP (FEU): Bauru-SP: Editora da Universidade do Sagrado Coração (EDUSC), 1999. 
SOUZA, Carlos Augusto da Silva; SILVA, Maria Dolores Lima da. Discursos divisionistas e criação de novos estados no Brasil: impactos no arranjo federativo. Revista Eletrônica Direito e Política, Programa de Pós-Graduação Stricto Sensu em Ciência Jurídica da UNIVALI, Itajaí, v.13, n.2, $2^{\circ}$ quadrimestre de 2018. Disponível em: www.univali.br/direitoepolitica - ISSN 1980-7791

de capitanias hereditárias; e o estado colonial do Maranhão, com sede em São Luís. Após a separação das Coroas Ibéricas, a partir de 1654, o antigo estado do Maranhão, que posteriormente passou a se chamar de Estado do Grão Pará e Maranhão, dividiu-se em quatro capitanias: Pará, Maranhão, Rio Negro (depois Amazonas) e Piauír.

Em 1772, a Coroa Portuguesa, como forma de melhor administrar a região Amazônica, divide o Estado do Grão Pará e Maranhão em duas unidades administrativas: o Estado do Grão-Pará e Rio Negro, com sede em Belém e o Estado do Maranhão e Piauí, com sede em São Luís. Com esta medida, a América Portuguesa passava a compreender três unidades administrativas autônomas: o Estado do Grão-Pará e Rio Negro, o Estado do Maranhão e Piauí e o Estado do Brasil. Dois anos depois, em 1774, como forma de unificar a administração colonial na América, a corte portuguesa resolve estabelecer apenas um estado na América, declarando a extinção do Estado do Maranhão e Piauí e do Estado do Grão-Pará e Rio Negro, sendo suas capitanias incorporadas ao Estado do Brasil e subordinadas ao Vice-rei do Brasil, com sede no Rio de Janeiro. Após a independência, o Brasil passou a contar com 18 províncias, sendo que até a proclamação da República, em 1891, somente duas novas províncias foram criadas: a do Amazonas, desmembrada do Pará, e a do Paraná, desmembrada de São Paulo.

Em 1903, a partir de um acordo com a Bolívia, o território do Acre foi incorporado ao Brasil, mediante o pagamento de uma indenização, bem como a cessão aos bolivianos de uma pequena área em Mato Grosso. O Acre foi transformado em território Federal, sendo administrado por representantes indicados diretamente pelo governo federal. Durante a II Guerra Mundial, sob os auspícios da ditadura Varguista, foram criados mais seis territórios federais em 1943: Amapá, Ponta Porã, Iguaçu, Rio Branco, Guaporé e Fernando de Noronha. Com a criação destes teritórios, diversos estados perderam parte de suas antigas possessões.

Com o término da guerra, os territórios de Ponta Porã e Iguaçu foram extintos e

6 VIEGAS, Nilza Gonçalves. A colonização portuguesa no Maranhão. 2010. Disponível em:http://eduardorodriguesbrito.blogspot.com/2010/06/espaco-maranhao.html

7 ANDRADE, Manuel Correia de. As Raízes do Separatismo no Brasil. p. 27-28. 
SOUZA, Carlos Augusto da Silva; SILVA, Maria Dolores Lima da. Discursos divisionistas e criação de novos estados no Brasil: impactos no arranjo federativo. Revista Eletrônica Direito e Política, Programa de Pós-Graduação Stricto Sensu em Ciência Jurídica da UNIVALI, Itajaí, v.13, n.2, $2^{\circ}$ quadrimestre de 2018. Disponível em: www.univali.br/direitoepolitica - ISSN 1980-7791

seus territórios foram devolvidos aos estados remanescentes, mas os demais foram mantidos (Rio Branco foi renomeado como Roraima e Guaporé batizado de Rondônia, em homenagem ao Marechal Rondon). Assim, a região amazônica passou a contar com mais três territórios federais, além dos estados do Pará e Amazonas e o já existente território do Acre. Apesar dos territórios federais integrarem a União, eles não eram considerados entes da federação, logo, não faziam parte da organização político-administrativa do país, não dispunham de autonomia política e não elegiam representantes para o Congresso Nacional ${ }^{8}$.

Em 1962 ocorre a transformação do território do Acre em estado, aproveitando-se de norma legal prevista no artigo 90 da Constituição de 1946, que determinava a elevação imediata dos territórios federais à condição de estado, tão logo as suas rendas se tornassem iguais à renda do estado de menor arrecadação. Com a elevação do Acre a estado, grupos políticos sediados nos demais territórios federais passaram a se mobilizar para também conquistar sua autonomia política. A pretensão autonomista destes territórios, entretanto, foi sufocada pela eclosão da ditadura militar, em 1964.

Com a instalação de uma ditadura, foi estabelecido um sistema de governo que tinha na centralização política e no rígido controle sobre os estados e municípios uma marca significativa. Assim, devido ao aparato legal instituído pela Constituição de 1967, não houve espaço de negociação para que as lideranças políticas incluíssem nas reformas políticas que se seguiram ao golpe militar qualquer projeto de autonomia e maior capacidade de organização e liberdade política e administrativa.

Na década de 1980, ganha destaque o processo de autonomia de Rondônia, que se deu sob a autoridade do então presidente João Batista Figueiredo. A transformação do território de Rondônia em estado se estabeleceu em face do intenso crescimento populacional e dos constantes conflitos resultantes da elevada migração ocorrida na região durante a aplicação da política de colonização

8 SANTOS, Jorge Paulo Pereira dos e GAMARSKI, Elen de Araujo Barcellos. (2007) Federalismo e municipalismo: a gestão do território amazônico, 2007. p. 24. 
SOUZA, Carlos Augusto da Silva; SILVA, Maria Dolores Lima da. Discursos divisionistas e criação de novos estados no Brasil: impactos no arranjo federativo. Revista Eletrônica Direito e Política, Programa de Pós-Graduação Stricto Sensu em Ciência Jurídica da UNIVALI, Itajaí, v.13, n.2, $2^{\circ}$ quadrimestre de 2018. Disponível em: www.univali.br/direitoepolitica - ISSN 1980-7791

estabelecida pelos governos militares $^{9}$.

Como forma de atenuar os conflitos sociais que fugiam do controle do governo federal e para distender as disputas políticas que se acirravam entre os grupos de interesse presentes no território de Rondônia, o presidente Figueiredo encaminhou ao Congresso Nacional projeto de lei complementar que promovia a elevação do território federal de Rondônia à condição de estado, o que ocorreu em 22 de dezembro de 1981.

Após a independência de Rondônia começa a reacender o desejo de autonomia de outras frações territoriais. Em 1985, no contexto do processo de restauração da democracia no Brasil, os debates por autonomia passaram a ganhar destaque na formação do estado democrático brasileiro, tendo sido reforçadas as teses sobre a necessidade de criação de um pacto federativo mais descentralizador e com maior autonomia para os estados e municípios.

Neste aspecto, diferentemente da ordem anterior que consolidou um pacto federativo altamente centralizador e com reduzida autonomia para estados e municípios, na nova ordem federativa emanada da Constituição de 1988 emerge um pacto marcado pela descentralização fiscal e pelo retorno de eleições diretas para governador, prefeitos e presidente da República ${ }^{10}$.

Assim, como consequência desse processo, governadores de estados e prefeitos de capitais, bem como determinados grupos de interesse, tornam-se agentes políticos fortes e com capacidade de negociação com o governo federal para a produção de políticas públicas de interesse das esferas subnacionais. Desse modo, do ponto de vista legal, instituíram-se novas relações entre os entes federados, que passaram a se pautar pelos princípios do compartilhamento das responsabilidades e pela colaboração recíproca ${ }^{11}$.

\footnotetext{
9 LIMA, Maria Helena Palmer. Evolução da divisão político-administrativa brasileira de 1940 a 2007. p. 82 e 86 .

${ }^{10}$ SILVA, Andréia F. da. Federalismo, descentralização, municipalização e direito à educação básica no Brasil. $2009 . \quad$ p. $42-64 . \quad$ Em: <http://www.anpae.org.br/congressos_antigos/simposio2009/33.pdf>.

${ }^{11}$ SOUZA, Carlos Augusto da S. e BENTES, Elizabeth dos S. Redivisão Territorial no Estado do
} 
SOUZA, Carlos Augusto da Silva; SILVA, Maria Dolores Lima da. Discursos divisionistas e criação de novos estados no Brasil: impactos no arranjo federativo. Revista Eletrônica Direito e Política, Programa de Pós-Graduação Stricto Sensu em Ciência Jurídica da UNIVALI, Itajaí, v.13, n.2, 20 quadrimestre de 2018. Disponível em: www.univali.br/direitoepolitica - ISSN 1980-7791

Como resultado desse processo, os grupos de interesses presentes nos territórios federais passaram a ocupar espaço na nova ordem federativa em formação, advogando a necessidade de transformação dos antigos territórios, altamente dependentes da União, em novos estados, com autonomia e capacidade para gerenciar suas demandas e problemas internos. Nesse sentido, sob o bojo das transformações em curso, possibilitadas pela redemocratização, os constituintes acabaram acatando a proposta de criação de novos estados, elevando os territórios federais de Roraima e Amapá à condição de estado e criando uma nova unidade federativa, o estado do Tocantins, desmembrado do estado de Goiás.

Foi somente após o processo de redemocratização, com o advento da base legal conferida pela Constituição de 1988, que diversas lideranças presentes em diversos outros fragmentos dos estados brasileiros passaram a se organizar buscando autonomia política e administrativa através de sua transformação em estado.

\section{OS PROJETOS DE CRIAÇÃo DE NOVOS ESTADOS NO BRASIL}

Na página da web da Câmara dos Deputados do Brasil identificamos diversas propostas de projetos de Decretos Legislativos objetivando a realização de plebiscito para a criação de novos estados.

QUADRO 1: PROPOSTAS DE PLEBISCITO PARA CRIAÇÃO DE NOVOS ESTADOS. 2017
\begin{tabular}{|l|l|l|l|l|}
\hline ANO & PROPOSTA & \multicolumn{1}{|c|}{ AUTOR/PART/EST } & \multicolumn{1}{|c|}{ SITUAÇÃo } & \multicolumn{1}{c|}{ Novo ESTADO } \\
\hline 1989 & PDC 36 & Asdrubal Bentes (PMDB/PA) & Arquivada & Estado de Carajás \\
\hline 1991 & PDC 120 & Hilário Coimbra (PTB/PA) & Tramitando & Estado de Tapajós * \\
\hline 2001 & PDC 947 & $\begin{array}{l}\text { Sebastião Madeira } \\
\text { (PSDB/MA) }\end{array}$ & $\begin{array}{l}\text { Pronta para } \\
\text { o Plenário }\end{array}$ & Estado do Maranhão do Sul. \\
\hline 2003 & PDC 19 & Welinton Fagundes (PL/MT) & Arquivada & $\begin{array}{l}\text { Estado de Mato Grosso do } \\
\text { Norte. }\end{array}$ \\
\hline 2003 & PDC 384 & $\begin{array}{l}\text { Gonzaga Patriota (PSB/PE) e } \\
\text { Outros }\end{array}$ & Tramitando & Estado do Rio São Francisco* \\
\hline 2003 & PDC 49 & Welinton Fagundes (PL/MT) & Tramitando & $\begin{array}{l}\text { Estado do Araguaia e do Mato } \\
\text { Grosso do Norte.* }\end{array}$ \\
\hline 2003 & PDC 105 & Rogério Silva (PPS/MT) & Arquivada & $\begin{array}{l}\text { Estado do Mato Grosso do } \\
\text { Norte }\end{array}$ \\
\hline 2003 & PDC 295 & José Divino (PMDB/RJ) & Arquivado & Estado da Guanabara \\
\hline 2003 & PDC 495 & Rogério Silva (PPS/MT) & $\begin{array}{l}\text { Pronta para } \\
\text { o Plenário }\end{array}$ & $\begin{array}{l}\text { Estado do Mato Grosso do } \\
\text { Norte* }\end{array}$ \\
\hline 2005 & PDC 1973 & João Magalhães (PMDB/MG) & Devolvida & Estado do Rio Doce. \\
\hline
\end{tabular}

Pará: Impactos econômicos e interesses políticos. Belém: UNAMA, (Relatório de Pesquisa), 2010. p. 34. 
SOUZA, Carlos Augusto da Silva; SILVA, Maria Dolores Lima da. Discursos divisionistas e criação de novos estados no Brasil: impactos no arranjo federativo. Revista Eletrônica Direito e Política, Programa de Pós-Graduação Stricto Sensu em Ciência Jurídica da UNIVALI, Itajaí, v.13, n.2, 20 quadrimestre de 2018. Disponível em: www.univali.br/direitoepolitica - ISSN 1980-7791

\begin{tabular}{|l|l|l|l|l|}
\hline 2005 & PDC 2036 & João Magalhães (PMDB/MG) & Arquivada & Estado do Rio Doce. \\
\hline 2010 & PDC 2718 & Átila Lins (PMDB/AM) & Devolvida & Estado do Alto Solimões \\
\hline 2011 & PDC 7 & Ribamar Alves (PSB/MA) & Devolvida & Estado do Maranhão do Sul. \\
\hline 2011 & PDC 231 & Ribamar Alves (PSB/MA) & $\begin{array}{l}\text { Tramitando } \\
\text { em conjunto }\end{array}$ & Estado do Maranhão do Sul. \\
\hline 2011 & PDC 355 & Oziel Oliveira (PDT/BA) & Arquivada & Estado do Rio São Francisco \\
\hline
\end{tabular}

$(*)$ Registrados como tramitando em conjunto.

Fonte: C.Dep. http://www.camara.leg.br/buscaproposicoesweb/pesquisasimplificada

Vemos no quadro acima que, na região norte, os projetos de criação dos estados do Tapajós e Carajás, que foram rejeitados em plebiscito em 2011, ainda aparecem em tramitação ${ }^{12}$. Isso ocorre porque existem movimentos de lideranças políticas que se mantêm vivos no Poder Legislativo a partir das iniciativas de lideranças regionais ${ }^{13}$.

Na região nordeste, há propostas de plebiscito para a criação do estado do Rio São Francisco e do estado do Maranhão do Sul, por exemplo; na região sudeste, há proposta de recriação do antigo estado da Guanabara, a partir da emancipação da cidade do Rio de Janeiro; e no centro-oeste, há movimentos emancipacionistas para a criação dos estados do Araguaia e Mato Grosso do Norte, a partir da emancipação do Mato Grosso.

Em trabalho da Consultoria Legislativa da Câmara dos Deputados do Brasil, Ana Tereza S. Duarte observa a existência de propostas e movimentos de criação de novas unidades federativas que envolvem todas as regiões do país ${ }^{14}$. Na região sul, diversos grupos de interesse defendem a criação do estado do Iguaçu, formado com parte dos estados do Paraná e Santa Catarina, e a concepção do estado do Pampa, desmembrado do Rio Grande do Sul.

Existiram também propostas para a criação do estado do Xingu, além da criação

12 Outros projetos de decreto legislativo da Câmara dos Deputados (PDC) são registrados como PDCs apensados, tais como o PDC 731/00, 731/2000, PDC 850/01. Também não está no quadro a tramitação de propostas de criação de territórios federais, como o PDV 1389/2004 (arquivado) de Almir Moura (PL/RJ), que propõe a criação dos territórios federais do Acre, do Amapá, do Amazonas, do Pará, de Rondônia, de Roraima, do Tocantins e do Mato Grosso.

13 Algumas propostas dão entrada mais de uma vez, por iniciativa do mesmo autor ou de outro deputado, e quando se trata de iniciativas de desmembramento no mesmo estado, há registro de tramitação conjunta. http://www.camara.leg.br/buscaproposicoesweb/pesquisasimplificada.

14 CÂMARA DOS DEPUTADOS DO BRASIL. Divisão territorial do Estado do Amazonas. Brasília: Câmara dos Deputados. Consultoria Legislativa, 2005. 
SOUZA, Carlos Augusto da Silva; SILVA, Maria Dolores Lima da. Discursos divisionistas e criação de novos estados no Brasil: impactos no arranjo federativo. Revista Eletrônica Direito e Política, Programa de Pós-Graduação Stricto Sensu em Ciência Jurídica da UNIVALI, Itajaí, v.13, n.2, $2^{\circ}$ quadrimestre de 2018. Disponível em: www.univali.br/direitoepolitica - ISSN 1980-7791

do território federal do Marajó do Alto Rio Negro, Madeira, Juruá e Uirapuru. No Amapá, já tramitou no Congresso Nacional proposta para a criação do Território Federal do Oiapoque.

A criação de um novo estado ou território federal não implica que ele integrará necessariamente a região político-administrativa da qual faz parte o estado que Ihe deu origem. O Tocantins, por exemplo, era parte centro-norte de Goiás que a partir da divisão, passou à região norte. O Maranhão do Sul também seria outro estado que, caso criado, sairia de sua região de origem, o Nordeste, passando a integrar a região norte.

Algumas das propostas de redivisão territorial foram arquivadas, seja porque os seus propositores não se reelegeram ou porque foram inviabilizadas nas comissões do Congresso Nacional. Outras foram apensadas em projetos anteriores que tratam da mesma matéria ou assunto correlato. Portanto, nem todas as propostas que deram entrada pós 1988 continuam tramitando no Congresso Nacional.

\section{OS DISCURSOS DIVISIONISTAS}

Os discursos que alimentam as atuais propostas de redivisão territorial são diversificados e não apresentam o mesmo significado no tempo e no espaço. Vão desde manifestações sobre as dimensões territoriais dos estados, quanto à necessidade de desenvolver regiões esquecidas pelo poder público, como ainda relacionada a questões de segurança nacional, além de razões culturais, políticas e geográficas.

$\mathrm{Na}$ fala dos atores políticos e agentes envolvidos com a questão da redivisão territorial há diversos discursos tanto favoráveis quanto contrários à criação de novos estados. Nesse sentido, o artigo procurou confrontar as duas posições políticas, tanto a dimensão do discurso favorável quanto a dimensão contrária à criação de novos estados no Brasil. Foram analisados seis temas presentes na fala dos atores sobre a criação de novos estados: Extensão Territorial, Desenvolvimento Econômico, Segurança Nacional, Redução dos Impactos Ambientais, Diversidade Cultural e Interesses Políticos. Alguns dos temas foram analisados conjuntamente com outro devido sua elevada correlação no tratamento 
SOUZA, Carlos Augusto da Silva; SILVA, Maria Dolores Lima da. Discursos divisionistas e criação de novos estados no Brasil: impactos no arranjo federativo. Revista Eletrônica Direito e Política, Programa de Pós-Graduação Stricto Sensu em Ciência Jurídica da UNIVALI, Itajaí, v.13, n.2, 20 quadrimestre de 2018. Disponível em: www.univali.br/direitoepolitica - ISSN 1980-7791

do discurso. Assim, o tema da extensão territorial foi analisado juntamente com o tema do desenvolvimento econômico, bem como o tema da segurança nacional foi analisado juntamente com o tema da redução dos impactos ambientais.

\subsection{O DISCURSO DA EXTENSÃO TERRITORIAL DOS ESTADOS E O DESENVOLVIMENTO ECONÔMICO}

Alguns dos argumentos que foram analisados vinculam fortemente a redivisão territorial a questões de natureza econômica, advogando a necessidade de descentralizar recursos e dinamizar de forma mais consistente regiões subdesenvolvidas que, por não disporem de força política, acabam desassistidas pelo poder público. A criação de novos estados, nesse sentido, seria uma necessidade para possibilitar maiores níveis de desenvolvimento, através da descentralização de recursos, e maior autonomia na alocação de investimentos que impactariam positivamente na geração de emprego e renda.

Esse discurso, somado ao das grandes dimensões territoriais dos estados, é utilizado na maioria dos projetos que desejam a criação de novas unidades territoriais na Amazônia15. O senador Mozarildo Cavalcante, por exemplo, autor de três projetos de redivisão territorial - Tapajós, Araguaia e Território Federal do Solimões -, argumenta que a grande dimensão geográfica dos estados dificulta a ação dos governos estadual e federal, condenando as populações dos municípios mais distantes dos centros decisórios a toda espécie de carências, especialmente às de prestações de serviços oferecidos pelo poder público, como saúde, saneamento, transportes e educação ${ }^{16}$. Além disso, a distância existente entre capital e alguns municípios do interior, principalmente em estados com elevada dimensão territorial, dificultaria a prestação de serviços básicos que se concentram expressivamente nas capitais.

Alguns analistas, entretanto, discordam desta observação, afirmando que não existe correlação positiva entre tamanho do território e desenvolvimento

15 CÂMARA DOS DEPUTADOS DO BRASIL. Divisão territorial do Estado do Amazonas. Brasília: Câmara dos Deputados. Consultoria Legislativa, 2005. p. 49-51

16 CAMPOS, André. O Brasil de roupa nova. ONG Repórter Brasil. 01/01/2005. p. 1. Disponível em: http://www.reporterbrasil.com.br/exibe.php?id=53 
SOUZA, Carlos Augusto da Silva; SILVA, Maria Dolores Lima da. Discursos divisionistas e criação de novos estados no Brasil: impactos no arranjo federativo. Revista Eletrônica Direito e Política, Programa de Pós-Graduação Stricto Sensu em Ciência Jurídica da UNIVALI, Itajaí, v.13, n.2, 20 quadrimestre de 2018. Disponível em: www.univali.br/direitoepolitica - ISSN 1980-7791

socioeconômico. Por exemplo, afirma-se que, caso se confirmasse a tese de que o tamanho territorial se apresenta como uma variável confiável para se estabelecer níveis de desenvolvimento econômico, estados como Sergipe e Alagoas, que são os menores estados do país em dimensão territorial, se constituiriam nos estados mais ricos e desenvolvidos do país. Entretanto, estes dois estados estão entre os mais pobres da federação. Em quase todos os estados brasileiros há problemas de desníveis de desenvolvimento entre a capital e interior, não sendo absolutamente verdadeiro o discurso de que a proximidade da capital facilite o acesso a recursos e a determinados serviços públicos ${ }^{17}$.

Outros analistas também observam que muitos estados sofrerão perdas com a distribuição das receitas oriundas das transferências intergovernamentais, pois muitos dos novos estados a serem criados não dispõem de autossuficiência financeira para bancar os custos que a redivisão traria, podendo agravar a situação dos que apresentam maior dependência das transferências federais. A criação de estados e territórios que não possuem autonomia financeira pode levar ao enfraquecimento da federação na medida em que estas novas unidades apresentam grande dependência de recursos transferidos pelo governo federal. Ademais, a criação de novos estados diminuiria a receita do Fundo de Participação dos Estados - FPE, que seria diluída entre as novas e antigas unidades políticoadministrativas causando ainda mais desequilíbrio entre os entes federados ${ }^{18}$.

Por outro lado, conforme discurso do deputado Eron Bezerra (PC do B - AM) e expresidente da Comissão de Assuntos Amazônicos, Meio Ambiente, Recursos Minerais e Hídricos da Assembleia Legislativa do Amazonas, os argumentos das perdas associadas às propostas divisionistas não são consistentes. Para ele, caso alguns estados e territórios venham a ser criados, determinados municípios das regiões emancipadas poderão ter sérios prejuízos com a perda dos repasses provenientes do Imposto sobre Circulação de Mercadorias e Serviços (ICMS) estadual, cuja receita é gerada quase que integralmente nas capitais dos estados.

\footnotetext{
17 SOUZA, Carlos Augusto da S. e BENTES, Elizabeth dos Santos. Redivisão Territorial no Estado do Pará: Impactos econômicos e interesses políticos. p. 42.
}

18 SANTOS, Fernando C. A. Segurança Nacional e Debilidade Institucional nas Fronteiras do Brasil com a Colômbia. Belém: UFPA, 2008. p. 64. Monografia de Graduação em economia. 
SOUZA, Carlos Augusto da Silva; SILVA, Maria Dolores Lima da. Discursos divisionistas e criação de novos estados no Brasil: impactos no arranjo federativo. Revista Eletrônica Direito e Política, Programa de Pós-Graduação Stricto Sensu em Ciência Jurídica da UNIVALI, Itajaí, v.13, n.2, 20 quadrimestre de 2018. Disponível em: www.univali.br/direitoepolitica - ISSN 1980-7791

Em seu exemplo, uma cidade como Atalaia do Norte, que em 2005 recebia um repasse de cerca de $\mathrm{R} \$ 2$ milhões relativo ao ICMS do Amazonas, se passar a integrar um território vai ter de viver com cerca de $\mathrm{R} \$ 5$ mil ou R\$ 6 mil por ano, o que é uma perda significativa para aquele município que depende quase que exclusivamente desse tipo de transferência governamental. Para o parlamentar, não existem estudos aprofundados sobre os reais impactos que 0 desmembramento poderá trazer para as áreas impactadas e a maioria das análises é influenciada por interesses políticos e econômicos, sem uma preocupação, até o momento, com os impactos sociais, ambientais e políticos que este tipo de proposta poderá trazer ${ }^{19}$.

\subsection{O DISCURSO DA SEGURANÇA NACIONAL E A REDUÇÃO DOS IMPACTOS AMBIENTAIS}

Na discussão sobre a redivisão territorial também estão presentes argumentos que a vinculam a um processo de garantia da soberania nacional sobre áreas estratégicas do território brasileiro. De acordo com esta interpretação, com ênfase para a questão da Amazônia, a defesa do patrimônio natural depende do controle sobre as fronteiras e de uma ocupação mais efetiva sobre áreas parcamente povoadas do território. Nesta situação, a criação de novas unidades administrativas teria a finalidade de garantir maior presença do poder público e maior capacidade de fiscalização que afiançasse a defesa do território e a proteção do homem e da natureza amazônica contra a invasão estrangeira.

Algumas das propostas de redivisão territorial como aquelas que promovem a criação dos territórios federais de Juruá, Solimões e Rio Negro, todos no oeste do estado do Amazonas, contam com o apoio das forças armadas. A área dos dois últimos fica na fronteira com o Peru, Colômbia e Venezuela, e apresenta notória vulnerabilidade à ação do narcotráfico e de guerrilhas, como as Forças Armadas Revolucionárias da Colômbia $(F A R C)^{20}$. Diante dessa realidade, alguns setores das

19 CÂMARA DOS DEPUTADOS DO BRASIL. Divisão territorial do Estado do Amazonas. Brasília: Câmara dos Deputados. Consultoria Legislativa, 2005. p. 52; CAMPOS, André. O Brasil de roupa nova.

20 SANTOS, Fernando C. A. Segurança Nacional e Debilidade Institucional nas Fronteiras do Brasil com a Colômbia. p. 67. 
SOUZA, Carlos Augusto da Silva; SILVA, Maria Dolores Lima da. Discursos divisionistas e criação de novos estados no Brasil: impactos no arranjo federativo. Revista Eletrônica Direito e Política, Programa de Pós-Graduação Stricto Sensu em Ciência Jurídica da UNIVALI, Itajaí, v.13, n.2, $2^{\circ}$ quadrimestre de 2018. Disponível em: www.univali.br/direitoepolitica - ISSN 1980-7791

forças armadas são favoráveis à criação dos territórios como meio de trazer desenvolvimento e adensamento populacional à região, visando a ocupação civil e a defesa das fronteiras.

Correa $^{21}$ discorda dessa observação, advertindo que não há garantias de que a redivisão territorial poderá gerar maior defesa do espaço e proteção do homem e da natureza. Para ele, na maioria das experiências de ocupação territorial há, efetivamente, um deslocamento de população para estas novas áreas, em busca de benefícios gerados pelos investimentos iniciais envolvidos com a criação de novos estados. Entretanto, o deslocamento populacional pode significar uma maior presença e diversificação de novos grupos de interesse e maior depredação do meio ambiente e da natureza, principalmente por elites econômicas interessadas na exploração da diversidade natural representada pelos recursos florestais e minerais disponíveis na Amazônia. Evidências dessa perspectiva estão no aumento do nível de desmatamento, poluição ambiental, contaminação de rios, etc. produzidos nas últimas décadas nas áreas impactadas por forte ocupação populacional. Estudo 22 realizado a pedido da Câmara dos Deputados concluiu não existir nenhuma relação entre os índices de desflorestamento relativo na região e a criação de estados. Rondônia, por exemplo, apresentou, nos últimos anos, estatísticas de desmatamento sensivelmente mais acentuadas que o Amazonas e o Pará, os maiores estados do país.

Arretche $^{23}$, em artigo denominado "Mitos da descentralização", alerta para o problema vinculado à ideia de que a mesma traria grandes vantagens de desenvolvimento. Para ela, esta ideia nem sempre corresponde à verdade, pois, a princípio, a proximidade entre provedores e usuários de serviços permite redução de custos, melhor informação, maior controle sobre gastos, etc. Mas essas vantagens são apenas potenciais, uma vez que não há nenhuma garantia de que

${ }^{21}$ CORREA, Antônio Carlos M. O Debate sobre a criação de novos estados no Brasil. Brasília: Brasília Jurídica, 2007. p. 1-140.

22 Campos observa que experiências passadas de reordenamento do território na Amazônia mostram que unidades federativas menores não necessariamente garantem melhoria dos indicadores ambientais. CAMPOS, André. O Brasil de roupa nova. p. 1.

${ }^{23}$ ARRETCHE, Marta T. S. Políticas sociais no Brasil: descentralização em um Estado federativo. Revista Brasileira de Ciências Sociais, vol.14, No 40, São Paulo, Jun. 1999. 
SOUZA, Carlos Augusto da Silva; SILVA, Maria Dolores Lima da. Discursos divisionistas e criação de novos estados no Brasil: impactos no arranjo federativo. Revista Eletrônica Direito e Política, Programa de Pós-Graduação Stricto Sensu em Ciência Jurídica da UNIVALI, Itajaí, v.13, n.2, 20 quadrimestre de 2018. Disponível em: www.univali.br/direitoepolitica - ISSN 1980-7791

a descentralização vá trazer tais resultados. Na verdade, é possível até que a descentralização possibilite a elevação dos níveis de corrupção e de ineficiência, caso não existam mecanismos efetivos de controle, fiscalização e acesso das pessoas ao Estado.

Por outro lado, também não há garantias de que a redivisão territorial produza como resultado a redução do narcotráfico nas áreas de fronteira, pois o controle do narcotráfico depende de políticas de monitoramento, controle e inteligência, e não apenas da criação de uma nova unidade federativa. Além do mais, não há como garantir que não haverá o recrutamento e o envolvimento da população local com os narcotraficantes.

A ação do tráfico está presente em cidades desenvolvidas, com baixa extensão territorial e com elevado padrão de desenvolvimento. Além de que as áreas territoriais destes novos estados continuarão tão extensas que, somadas às enormes demandas sociais que surgirão com a formação de novos estados, dificilmente sobrará muito capital para investimento em monitoramento de fronteira ${ }^{24}$.

Neste campo também não há estudos eficientes que comprovem a relação direta entre ocupação e defesa e controle das áreas de fronteira. Problemas como monitoramentos das fronteiras são constantes em regiões desenvolvidas, como Foz do Iguaçu, Oeste de Mato Grosso, Rio Grande do Sul, entre outros.

\subsection{O DISCURSO DA DIVERSIDADE CULTURAL}

Há estudos que vinculam a questão da redivisão territorial à falta de unidade entre grupos sociais culturalmente diversos. Para esta corrente, o Brasil não se constitui como uma nação bem sólida e amalgamada com uma solidariedade entre pessoas e culturas diversas, mas um aglomerado de grupos sociais heterogêneos que, muitas vezes, ocupam uma mesma área, mas não sentem solidariedade entre si.

Manuel Correa de Andrade ${ }^{25}$, em seu livro "As raízes do separatismo no Brasil",

\footnotetext{
${ }^{24}$ CORREA, Antônio Carlos M. O Debate sobre a criação de novos estados no Brasil. p. 52.

${ }^{25}$ ANDRADE, Manuel Correia de. As Raízes do Separatismo no Brasil. p. 18.
} 
SOUZA, Carlos Augusto da Silva; SILVA, Maria Dolores Lima da. Discursos divisionistas e criação de novos estados no Brasil: impactos no arranjo federativo. Revista Eletrônica Direito e Política, Programa de Pós-Graduação Stricto Sensu em Ciência Jurídica da UNIVALI, Itajaí, v.13, n.2, $2^{\circ}$ quadrimestre de 2018. Disponível em: www.univali.br/direitoepolitica - ISSN 1980-7791

explica que o processo histórico de ocupação do país sempre foi marcado pela presença de um multiculturalismo que alimenta as ideias separatistas. Para ele, as raízes desse processo remontam à época do descobrimento, onde grupos indígenas rivais já lutavam pelo controle de faixas territoriais estratégicas. Depois vieram os primeiros fluxos de negros e portugueses com interesses e motivações diferenciadas. No decorrer do processo de formação da sociedade brasileira, levas de imigrantes das mais diversas nacionalidades - espanhóis, alemães, italianos, açorianos, judeus, japoneses, chineses, coreanos, entre outros - vieram somar-se aos grupos étnicos já estabelecidos. Juntando-se a isso as migrações internas como a dos nordestinos - , tem-se o caldo cultural de uma sociedade desarmônica, latente em todo o Brasil.

No caso da Amazônia, nas últimas décadas, houve intensa migração de grupos externos à região, portadores de valores, culturas, tradições e linguagens próprias, diferentes das populações tradicionais que nasceram e habitam a região e se reconhecem como amazônidas. Sendo em sua maioria migrante, esta população não se vê nos valores e tradições locais e não possui vínculos culturais sólidos com as populações tradicionais. Por esta razão, é de se entender que esses grupos não se sintam inteiramente vinculados às raízes locais e não comunguem dos mesmos sistemas de valores, tradições e culturas historicamente e socialmente construídos.

Rodrigues $^{26}$ afirma que a cultura, entendendo-se esta como a soma de costumes, tradições e valores que caracterizam determinada comunidade, se reforça como um jeito próprio de ser, estar e sentir o mundo, jeito este que leva o indivíduo a fazer, ou a expressar-se, de forma característica. Para a autora, SER é também PERTENCER - a algum lugar, a alguma fé ou a um grupo, seja família, amigos ou povo. Daí ser a cultura um forte agente de identificação pessoal e social, um modelo de comportamento que integra segmentos sociais e gerações, uma terapia afetiva que desperta os recursos internos do indivíduo e fomenta sua interação com o grupo, sendo um fator essencial na construção de vínculos com outros

${ }^{26}$ RODRIGUES, Sonia Regina Rocha. A Importância da Cultura na Formação do Cidadão. São paulo, USP, 2006. p. 72-74. 
SOUZA, Carlos Augusto da Silva; SILVA, Maria Dolores Lima da. Discursos divisionistas e criação de novos estados no Brasil: impactos no arranjo federativo. Revista Eletrônica Direito e Política, Programa de Pós-Graduação Stricto Sensu em Ciência Jurídica da UNIVALI, Itajaí, v.13, n.2, 20 quadrimestre de 2018. Disponível em: www.univali.br/direitoepolitica - ISSN 1980-7791

indivíduos.

Por outro lado, na medida em que o indivíduo se realiza como pessoa e expande suas potencialidades, a percepção individual do mundo é influenciada pelo grupo. Aquilo que o grupo aprova ou valoriza tende a ser selecionado na percepção pessoal; já o que é rejeitado ou indiferente aos valores do grupo tem menor possibilidade de ser selecionado pela percepção do sujeito - e se for significativa para o sujeito, este o guarda para si ou o elabora de forma a adaptá-lo aos valores grupais, de maneira lúdica, simbólica ou distorcida, no intuito de evitar a censura coletiva.

Com base nos argumentos acima, pode-se concluir que as transformações recentes que se processaram na base demográfica da Amazônia, cuja marca mais expressiva é a diversidade de atores e de culturas incorporadas na geografia política da região, tornam-se importantes para entender o desejo de autonomia.

Souza27, em um trabalho sobre a geografia do voto no estado do Pará, afirma que a distribuição dos votos entre as regiões geográficas do estado tem a marca da diversidade cultural estabelecida pela migração. Regiões que concentram, por exemplo, uma elevada fração de populações provenientes do Nordeste, como é o caso do Sudeste do Pará, tendem a eleger candidatos que tenham afinidades com os atributos socioculturais da população nordestina. Isto se estabelece pelo fato de que os eleitores, principalmente no plano local, geralmente procuram candidatos com o mesmo sistema de valor e com as mesmas identidades coletivas, baseados em experiências e situações da vida em comum, que permitam reconhecer o líder como um suposto aliado.

Assim, não se torna difícil para algumas lideranças seduzir eleitores para a questão do separatismo enquanto principal alternativa para a resolução dos problemas e afirmação de uma nova identidade na região ${ }^{28}$. Por esta razão, separar os espaços

27 SOUZA, Carlos Augusto da S. Geografia eleitoral e padrões de competição política no estado do Pará. Rio de Janeiro: IUPERJ, (Tese). 2006. p. 46-50.

28 MORBACH investiga as preferências separatistas na região de Carajás (PA) a partir de entrevistas com vereadores dos municípios da região, destacando o perfil social de descendentes de imigrantes e a preferência dos mesmos pela separação do Pará em mais de $90 \%$ dos entrevistados. MORBACH, Maria da Conceição Bezerra. As perspectivas políticas da criação do estado de Carajás a partir 
SOUZA, Carlos Augusto da Silva; SILVA, Maria Dolores Lima da. Discursos divisionistas e criação de novos estados no Brasil: impactos no arranjo federativo. Revista Eletrônica Direito e Política, Programa de Pós-Graduação Stricto Sensu em Ciência Jurídica da UNIVALI, Itajaí, v.13, n.2, 20 quadrimestre de 2018. Disponível em: www.univali.br/direitoepolitica - ISSN 1980-7791

se constitui numa estratégia de afirmação da identidade e valorização desta nova cultura e dos novos padrões de sociabilidade que estão sendo construídos ao longo do tempo em diversas regiões da Amazônia.

\subsection{O DISCURSO DOS INTERESSES POLÍTICOS}

Por fim, há aqueles que afirmam existir uma correlação estreita entre redivisão territorial e interesses de determinadas lideranças políticas em conquistar maiores espaços de poder ${ }^{29}$. Para esta interpretação, a criação de novos estados tem como resultado o conflito entre elites econômicas e políticas pelo controle do território.

Em vez de disputar espaços de poder com elites fortes e consolidadas, torna-se muito mais atraente para algumas lideranças incluir na agenda a bandeira do separatismo, pois além da força que o argumento possui na mobilização do eleitorado, permite a acomodação e a diminuição das disputas políticas entre grupos rivais, a partir da criação de novos cargos políticos que não serão disputados com forças políticas tradicionais dos estados remanescentes. De acordo com esta situação, o desmembramento territorial tem como objetivo principal delimitar e controlar espaços de poder.

Nesta interpretação é válido destacar o entendimento estabelecido por Castilho ${ }^{30}$, que afirma ser o território palco de lutas e conflitos entre forças políticas divergentes que buscam aumentar ou manter diversas formas e graus de poder sobre o território, sendo que, nesse processo, a delimitação de áreas de atuação tem se constituído como uma estratégia de neutralização das rivalidades, levando grupos sociais "vitoriosos" a organizar o espaço em seu proveito. Esta perspectiva considera o espaço como lócus de disputas para o exercício do poder e, por

do ponto de vista das representações parlamentares municipais. Dissertação (Mestrado em Ciência Política). Programa de Pós Graduação em Ciência Política. Universidade Federal do Pará. Belém, 2013.

${ }^{29}$ SOUZA, Carlos Augusto da S. e BENTES, Elizabeth dos Santos. Redivisão Territorial no Estado do Pará: Impactos econômicos e interesses políticos; SANTOS, João Augusto Farias dos. Elites políticas e separatismo no Pará: Uma análise política das Frentes Pró-Carajás e Tapajós para a criação de novos estados. Dissertação (Mestrado em Ciência Política). Programa de Pós Graduação em Ciência Política. Universidade Federal do Pará. Belém, 2012.

30 CASTILHO, Cláudio Jorge Moura de. Quando o espaço se torna locus de disputa de poderes: ensaio sobre uma geopolítica urbana em Recife/PE. Revista de Geografia. Recife: UFPE DCG/NAPA, v. 26, No 2, mai/ago. 2009. p. 86-88. 
SOUZA, Carlos Augusto da Silva; SILVA, Maria Dolores Lima da. Discursos divisionistas e criação de novos estados no Brasil: impactos no arranjo federativo. Revista Eletrônica Direito e Política, Programa de Pós-Graduação Stricto Sensu em Ciência Jurídica da UNIVALI, Itajaí, v.13, n.2, 20 quadrimestre de 2018. Disponível em: www.univali.br/direitoepolitica - ISSN 1980-7791

conseguinte, para a concretização de determinados objetivos e intenções que influenciam as decisões do poder não somente do Estado, mas também de outros atores e agentes sociais que tentam construir sua hegemonia.

É nesse sentido que algumas interpretações afirmam que o discurso da redivisão territorial apresenta em seu interior motivação política, onde os atores possuem interesse em aumentar seu controle sobre o território. A divisão dos estados é favorável porque possibilita reduzir as oposições e estabelecer melhores condições na produção de políticas públicas de interesse local. A criação de novos estados induziria o surgimento de um novo poder executivo e uma nova assembleia legislativa que teriam melhores condições de atender às demandas dos grupos de interesse da região em questão.

No caso do Pará, lideranças políticas ${ }^{31}$ contrárias à criação dos estados de Carajás e Tapajós afirmam que por trás do discurso divisionista está o interesse de grandes empresas (madeireiras, agropecuárias, mineradoras), que procuram mecanismos para controlar o poder político como forma de melhor atender a seus interesses. A Vale, por exemplo, uma das maiores mineradoras do mundo, tem continuadamente influenciado nas eleições municipais do estado, principalmente nos municípios em cujo território se concentram recursos naturais de interesse comercial da empresa. É claro que a criação de um novo estado geraria melhores condições para o gerenciamento do espaço e dos recursos naturais ${ }^{32}$.

\footnotetext{
${ }^{31}$ Antes do plebiscito de 2011 no estado do Pará, o Tribunal Superior Eleitoral determinou a criação de frentes pluripartidárias para disciplinar a exposição das ideias favoráveis e contrárias à emancipação dos estados do Carajás e Tapajós. MORBACH, Maria da Conceição Bezerra. As perspectivas políticas da criação do estado de Carajás a partir do ponto de vista das representações parlamentares municipais. p. 6.
}

32 SOUZA, Carlos Augusto da S. e BENTES, Elizabeth dos Santos. Redivisão Territorial no Estado do Pará: Impactos econômicos e interesses políticos. p. 35-36 
SOUZA, Carlos Augusto da Silva; SILVA, Maria Dolores Lima da. Discursos divisionistas e criação de novos estados no Brasil: impactos no arranjo federativo. Revista Eletrônica Direito e Política, Programa de Pós-Graduação Stricto Sensu em Ciência Jurídica da UNIVALI, Itajaí, v.13, n.2, 20 quadrimestre de 2018. Disponível em: www.univali.br/direitoepolitica - ISSN 1980-7791

\section{CONFLITOS FEDERATIVOS DA REDIVISÃO TERRITORIAL}

Uma avaliação importante que não tem sido considerada nas discussões sobre a criação de novas unidades territoriais no Brasil é justamente o impacto que estas propostas trarão para o pacto federativo. Pelo desenho institucional atualmente estabelecido, o país é uma federação formada pela união de 26 estados mais o distrito federal.

O federalismo é um modelo de soberania partilhada, construído a partir das diversidades culturais, das grandes distâncias de um país continental e da dispersão populacional do mesmo. Para que haja uma federação é necessário que exista uma parceria entre os entes federativos, municípios e estados, que pressupõe uma divisão de poderes entre os entes parceiros, autonomia delimitada para cada um deles e um relacionamento com o poder central que assegure uma adequada divisão de recursos, fortalecendo as conexões entre as diversas esferas de governo ${ }^{33}$.

Para Castro ${ }^{34}$, o pacto federativo é, por definição, um pacto de base territorial, no qual grupos localizados organizam-se em busca da harmonização entre suas demandas particulares e os interesses gerais. Dessa forma, o processo de construção da federação deve estabelecer uma estrutura dualista, que permita, ao mesmo tempo, fortalecer o poder da União, criando mecanismos de centralização do poder político, mas, também, a conferência de maior autonomia e maior liberdade aos estados na resolução dos seus problemas específicos.

O objetivo da federação consiste em criar mecanismos de unidade na diversidade, possibilitando cooperação, liberdade e igualdade entre os entes federados. Entretanto, para o autor, há uma constante tensão no estabelecimento da federação devido à diversidade de interesses presentes em cada estado e a difícil conciliação entre grupos muitas vezes antagônicos. Por esta razão, a federação

\footnotetext{
33 SANTOS, Julio Cesar Ferreira. As questões de limites interestaduais do Brasil: transição política e instabilidade do território nacional na Primeira República (1889-1930). Scripta Nova. Revista electrónica de geografía y ciencias sociales. Barcelona: Universidad de Barcelona, 1 de agosto de 2006, vol. X, núm. 218 (17).

${ }^{34}$ CASTRO, Iná Elias de. Solidariedade territorial e representação. Novas questões para o pacto federativo nacional. Revista Território, 1997. p. 82-84.
} 
SOUZA, Carlos Augusto da Silva; SILVA, Maria Dolores Lima da. Discursos divisionistas e criação de novos estados no Brasil: impactos no arranjo federativo. Revista Eletrônica Direito e Política, Programa de Pós-Graduação Stricto Sensu em Ciência Jurídica da UNIVALI, Itajaí, v.13, n.2, $2^{\circ}$ quadrimestre de 2018. Disponível em: www.univali.br/direitoepolitica - ISSN 1980-7791

deve ser precedida por arranjos institucionais que possibilitem acomodar os interesses e conciliar os conflitos.

O sucesso de uma estrutura federativa deve apoiar-se na definição clara das competências conferidas à União e aos estados, através de arranjos institucionais que garantam o exercício pleno do poder por cada uma dessas esferas e possibilitem a utilização de mecanismos de resolução dos conflitos com a participação social, mediada por instrumentos democraticamente conhecidos e aceitos por todos. Além disso, a federação deve apoiar-se no princípio da separação dos poderes, que leve à convivência pacífica entre os entes federados e os grupos de interesse presentes no território. Da mesma forma, o pacto federativo deve apoiar-se na construção de um Congresso Nacional que expresse a diversidade social e respeite os interesses dos diversos estados que compõem a federação.

Entretanto, o debate separatista encontra um grande entrave sobre como compatibilizar o desejo emancipacionista com a manutenção do pacto federativo de uma soberania compartilhada e de uma igualdade entre os entes federados. Como exemplo, podemos citar o caso da região norte do Brasil, que incorpora sete estados dos 26 que compõem a federação brasileira e apresenta uma população correspondente a apenas $8,0 \%$ da população total do país. Esta região possui a menor densidade demográfica da federação e, apesar de deter a maior porção territorial, com 45,2\% do território nacional, possui apenas 8,0\% dos municípios brasileiros.

Tabela 1 - Divisão Político-Administrativo do Brasil por regiões (2015)

\begin{tabular}{l|c|c|c|c|c}
\hline Regiões do Brasil & Área \% & População \% & PIB \% & $\begin{array}{c}N^{0} \text { de } \\
\text { Estados }\end{array}$ & $\begin{array}{c}N^{0} \text { de } \\
\text { Municípios }\end{array}$ \\
\hline Região Norte & 45,2 & 8,0 & 5,1 & 7 & 450 \\
Região Nordeste & 18,2 & 28,0 & 13,3 & 9 & 1793 \\
Região Centro-Oeste & 18,9 & 7,2 & 9,1 & $3 *$ & 466 \\
Região Sudeste & 10,6 & 42,3 & 55,7 & 4 & 1668 \\
Região Sul & 6,8 & 14,5 & 16,8 & 3 & 1188 \\
\hline
\end{tabular}

(*) Não computado o Distrito Federal Fonte: IBGE 
SOUZA, Carlos Augusto da Silva; SILVA, Maria Dolores Lima da. Discursos divisionistas e criação de novos estados no Brasil: impactos no arranjo federativo. Revista Eletrônica Direito e Política, Programa de Pós-Graduação Stricto Sensu em Ciência Jurídica da UNIVALI, Itajaí, v.13, n.2, $2^{\circ}$ quadrimestre de 2018. Disponível em: www.univali.br/direitoepolitica - ISSN 1980-7791

Por outro lado, a região norte participa da composição do poder legislativo nacional com 65 deputados federais eleitos nos sete estados da região. Segundo a Constituição brasileira, o número de representantes por estado deveria estar distribuído proporcionalmente ao número de habitantes de cada unidade federada. Entretanto, essa proporcionalidade é limitada a um mínimo de oito deputados e a um máximo de setenta deputados por estado. Esta limitação entre o número máximo e mínimo de deputados tem produzido intenso debate sobre a desproporcionalidade na alocação de cadeiras entre os estados brasileiros ${ }^{35}$.

Estados com elevada população estão subrepresentados na Câmara dos Deputados, enquanto os que possuem reduzida população estão sobrerepresentados na formação das bancadas legislativas ${ }^{36}$. Caso fosse seguida a premissa da proporcionalidade entre representação territorial e população, o estado de São Paulo, por exemplo, deveria ter direito a eleger mais 42 deputados federais além dos 70 que já elege. Já o estado de Roraima elegeria apenas um deputado federal.

Roraima, de acordo com as projeções populacionais do IBGE publicadas em junho de 2015, apresentava cerca de 505.665 habitantes (cerca de 0,9\% da população brasileira) e elege oito deputados federais, cerca de um deputado para cada 63.208 habitantes. Já São Paulo, que apresenta uma população com cerca de 44.396.484 (cerca de $21,7 \%$ da população brasileira), elege 70 deputados, numa proporção de um deputado para cada 634.235 habitantes. Ou seja, a eleição de apenas um deputado por São Paulo é maior que a população total do estado de Roraima, o que ilustra a grande distorção no princípio da proporcionalidade na alocação de cadeiras entre os estados.

A região norte, que apresenta uma das mais reduzidas dimensões populacionais da federação brasileira, beneficia-se da distorção na representação territorial na formação da Câmara dos Deputados. A referida região conta com 65 deputados

\footnotetext{
35 SOARES, Márcia Miranda e LOURENÇO, Luiz Cláudio. A representação política dos estados na federação brasileira. Revista brasileira de Ciências Sociais, vol.19 no 56, São Paulo outubro de 2004.

36 SENADO FEDERAL DO BRASIL. Sobre a representação dos estados na Câmara dos Deputados. Brasília: Consultoria Legislativa do Senado Federal, Texto para discussão No 5, 2004.
} 
SOUZA, Carlos Augusto da Silva; SILVA, Maria Dolores Lima da. Discursos divisionistas e criação de novos estados no Brasil: impactos no arranjo federativo. Revista Eletrônica Direito e Política, Programa de Pós-Graduação Stricto Sensu em Ciência Jurídica da UNIVALI, Itajaí, v.13, n.2, $2^{\circ}$ quadrimestre de 2018. Disponível em: www.univali.br/direitoepolitica - ISSN 1980-7791

federais, mas o número que corresponderia à sua representação adequada, do ponto de vista aritmético, seria 41. A partir destes dados, atualizamos os dados para 2015, conforme tabela abaixo.

Tabela 2. Representação Atual x Representação Real na Câmara dos Dep. (2015)

\begin{tabular}{l|r|r|r|r}
\hline \multirow{2}{*}{ Região } & \multicolumn{2}{|c|}{ Representação Atual } & \multicolumn{2}{c}{ Representação Real } \\
\cline { 2 - 5 } & Freq. & $\%$ & Freq. & $\%$ \\
\hline Região Norte & 65 & 12,7 & 41 & 7,9 \\
Região Nordeste & 151 & 29,4 & 144 & 27,9 \\
Região Centro-Oeste & 41 & 8,0 & 35 & 6,8 \\
Região Sudeste & 179 & 34,9 & 220 & 42,6 \\
Região Sul & 77 & 15,0 & 77 & 14,9 \\
\hline
\end{tabular}

Fonte: IBGE/TSE

O estabelecimento de piso e teto na representação dos estados, combinado com a criação de novos estados, alterou significativamente a desproporcionalidade entre as regiões. A região norte teve expressivo aumento na sua representação parlamentar a partir de 1978, atingido o ápice de sobrerepresentação em 1990, após a Constituição de 1988, quando a região ganhou três novos estados. A contrapartida parece ser a perda relativa de representação da região sudeste no mesmo período.

Além disso, a criação de novos estados tem impacto ainda mais profundo na representação do Senado, que é paritária entre os estados. Nesse sentido, cada novo estado terá direito a mais três senadores, o que aumentaria ainda mais a desproporcionalidade apresentada pelo pacto federativo. Caso fossem criados os estados de Carajás e Tapajós, por exemplo, haveria uma grande desproporcionalidade no poder das bancadas no Senado Federal, pois a bancada de senadores representantes da região norte passaria a ser maior do que a do Sudeste e isso faria com que o Norte tivesse enorme poder de veto de propostas de interesse dos estados sulistas, com maior população e maior representação na Câmara dos Deputados ${ }^{37}$.

37 SOARES, Márcia Miranda e LOURENÇO, Luiz Cláudio. A representação política dos estados na federação brasileira. p. 39-42. 
SOUZA, Carlos Augusto da Silva; SILVA, Maria Dolores Lima da. Discursos divisionistas e criação de novos estados no Brasil: impactos no arranjo federativo. Revista Eletrônica Direito e Política, Programa de Pós-Graduação Stricto Sensu em Ciência Jurídica da UNIVALI, Itajaí, v.13, n.2, $2^{\circ}$ quadrimestre de 2018. Disponível em: www.univali.br/direitoepolitica - ISSN 1980-7791

É necessário levar em consideração o impacto que novas unidades federativas trariam sobre as já consideráveis distorções de representatividade existentes no parlamento brasileiro. A criação de novos estados com reduzidos contingentes populacionais aumentaria, ainda mais, a desproporcionalidade na alocação de cadeiras entre os estados da federação, contrariando as premissas estabelecidas no pacto federativo.

Os reais motivos que envolvem a criação de novos estados estão nas vantagens políticas e econômicas proporcionadas a qualquer localidade que se torna um estado, sobretudo as menos populosas e mais pobres ${ }^{38}$. A principal vantagem política é o aumento da representação no governo federal: três senadores e oito deputados federais. Entre as vantagens econômicas, destacam-se: a assunção de competências tributárias exclusivas - Imposto sobre a Propriedade de Veículos Automotores (IPVA), Imposto sobre a Circulação de Mercadoria e Serviços (ICMS) e Imposto sobre a Transmissão de Bens Imóveis Causa Mortis (ITCD); a garantia de uma cota-parte do Fundo de Participação dos Estados (FPE); além de uma maior força política para barganhar recursos junto ao governo federal.

Em suma, a lógica dessas vantagens é extremamente perversa: quanto menos populosa e mais pobre a região maiores os incentivos em se tornar estado, sendo sedutora a ideia de autonomia em uma região com essas características.

\section{CONSIDERAÇÕES FINAIS}

As discussões sobre a redivisão territorial no Brasil vêm sendo motivo de preocupação dos legisladores desde a proclamação da República, mobilizando os grupos de interesse e produzindo acalorados debates contra ou a favor da fragmentação territorial, seja com a criação de novos estados, territórios federais ou novos municípios. A maioria das constituições que o país já teve, procurou, de alguma forma, recolocar a questão da redivisão territorial na agenda pública, seja para atender alguns interesses ou para impor limites a ação de grupos que pudessem comprometer as bases do pacto federativo brasileiro.

38 MARTINS, Herbert Toledo. A Fragmentação do Território Brasileiro: a criação de novos estados no Brasil. Caderno CRH, Salvador, n. 35, 2001. p. 263-288. 
SOUZA, Carlos Augusto da Silva; SILVA, Maria Dolores Lima da. Discursos divisionistas e criação de novos estados no Brasil: impactos no arranjo federativo. Revista Eletrônica Direito e Política, Programa de Pós-Graduação Stricto Sensu em Ciência Jurídica da UNIVALI, Itajaí, v.13, n.2, $2^{\circ}$ quadrimestre de 2018. Disponível em: www.univali.br/direitoepolitica - ISSN 1980-7791

Apesar de adormecido, em função dos longos períodos de interrupção da democracia, que limitaram a ação política de determinados grupos, o debate sobre a criação de novos estados, retomou lugar destacado nas últimas décadas em razão das transformações produzidas pela redemocratização do país, que ao possibilitar a inclusão de novos grupos de interesse na política nacional, ofereceu possibilidades para que a luta por autonomia assumisse grande importância na agenda pública.

Atualmente existem diversos projetos em tramitação no Congresso Nacional que procuram reduzir os limites das fronteiras dos atuais estados brasileiros com a criação de novas unidades administrativas. Apesar de se constituir como manifestação legítima, devido à diversidade social do Brasil e os grandes desníveis sociais existentes, o separatismo também implica o olhar sobre os interesses políticos e a viabilidade econômica destas novas unidades a serem criadas, pois a gênese de sentimentos separatistas encontra apoio em argumentos diferenciados, econômicos, culturais, ambientais, entre outros.

Entretanto, não obstante os interesses e motivações que alimentam as propostas de redivisão territorial torna-se de fundamental importância avaliar os impactos políticos que a criação de novas unidades federativas trará para o já debilitado pacto federativo nacional.

Nesse sentido, torna-se necessário um debate mais realista sobre o problema, pois as propostas de criação de novos estados envolvem em seu conteúdo discursos que ignoram os reais impactos sobre a federação como um todo. Além de comprometer a proporcionalidade no sistema de representação, a criação de novos estados não assegura que serão criadas políticas públicas que venham beneficiar todos os segmentos mobilizados para sustentar a proposta separatista.

\section{REFERÊNCIA DAS FONTES CITADAS}

ANDRADE, Manuel Correia de. As Raízes do Separatismo no Brasil. São Paulo: Fundação Editora da UNESP (FEU); Santa Catarina: Editora da Universidade do Sagrado Coração (EDUSC), 1999.

ARRETCHE, Marta T. S. Políticas sociais no Brasil: descentralização em um Estado federativo. Revista Brasileira de Ciências Sociais, vol.14, No 40, SP, Jun. 
SOUZA, Carlos Augusto da Silva; SILVA, Maria Dolores Lima da. Discursos divisionistas e criação de novos estados no Brasil: impactos no arranjo federativo. Revista Eletrônica Direito e Política, Programa de Pós-Graduação Stricto Sensu em Ciência Jurídica da UNIVALI, Itajaí, v.13, n.2, 20 quadrimestre de 2018. Disponível em: www.univali.br/direitoepolitica - ISSN 1980-7791

1999.

CÂMARA DOS DEPUTADOS DOS BRASIL. Divisão territorial do Estado do Amazonas. Brasília: Câmara dos Deputados. Consultoria Legislativa, 2005. Disponível em: http://www2.camara.gov.br/documentos-epesquisa/publicacoes/estnottec/tema14/2004_4464.pdf.

CAMPOS, André. O Brasil de roupa nova. ONG Repórter Brasil. 01/01/2005. Disponível em: http://www.reporterbrasil.com.br/exibe.php?id=53.

CASTILHO, Cláudio Jorge M. de. Quando o espaço se torna locus de disputa de poderes: ensaio sobre uma geopolítica urbana em Recife/PE. Revista de Geografia. Recife: UFPE - DCG/NAPA, v. 26, No 2, mai/ago. 2009.

CASTRO, Iná Elias de. Solidariedade territorial e representação. Novas questões para o pacto federativo nacional. Revista Território, 1997. Disponível em: http://www.revistaterritorio.com.br/pdf/02_4_castro.pdf.

CORREA, Antonio Carlos M. O Debate sobre a criação de novos estados no Brasil. Brasília: Brasília Jurídica, 2007.

KAERCHER, Nestor A. Separatismo: Autonomia x autoritarismo ou através da fala dos adolescentes questionamos o senso comum. Boletim Gaúcho de Geografia, 19: 21-30, maio 1992.2 Disponível em http://seer.ufrgs.br/bgg/article/view/38012/24494

LIMA, Maria Helena Palmer. Evolução da divisão político-administrativa brasileira de 1940 a 2007. Brasília: Instituto Brasileiro de Geografia e Estatística, 2011. Disponível em: http://biblioteca.ibge.gov.br/visualizacao/livros/liv47603_cap4_pt2.pdf.

MARTINS, Herbert Toledo. A Fragmentação do Território Brasileiro: a criação de novos estados no Brasil. Caderno CRH, Salvador, n. 35, 2001. p. 263-288. Disponível em: http://www4.fct.unesp.br/ceget/t34.pdf

MORBACH, Maria da Conceição Bezerra. As perspectivas políticas da criação do estado de Carajás a partir do ponto de vista das representações parlamentares municipais. Dissertação (Mestrado em Ciência Política). Programa de Pós Graduação em Ciência Política. Universidade Federal do Pará. Belém, 2013.

SENADO FEDERAL DO BRASIL. Sobre a representação dos estados na Câmara dos Deputados. Brasília: Consultoria Legislativa do Senado Federal, Texto para discussão nº 5, 2004.

RODRIGUES, Sonia Regina R.. A Importância da cultura na formação do cidadão. São paulo, USP, $2006 . \quad$ Disponível em:www.qdivertido.com.br/verartigo.php?codigo $=57$

SANTOS, Fernando C. A. Segurança Nacional e Debilidade Institucional nas 
SOUZA, Carlos Augusto da Silva; SILVA, Maria Dolores Lima da. Discursos divisionistas e criação de novos estados no Brasil: impactos no arranjo federativo. Revista Eletrônica Direito e Política, Programa de Pós-Graduação Stricto Sensu em Ciência Jurídica da UNIVALI, Itajaí, v.13, n.2, $2^{\circ}$ quadrimestre de 2018. Disponível em: www.univali.br/direitoepolitica - ISSN 1980-7791

Fronteiras do Brasil com a Colômbia. Belém: UFPA, 2008. (Monografia de Graduação em Economia)

SANTOS, João Augusto Farias dos. Elites políticas e separatismo no Pará: Uma análise política das Frentes Pró-Carajás e Tapajós para a criação de novos estados. Dissertação (Mestrado em Ciência Política). Programa de Pós Graduação em Ciência Política. Universidade Federal do Pará. Belém, 2012.

SANTOS, Jorge Paulo Pereira dos e GAMARSKI, Elen de Araujo Barcellos. (2007) Federalismo e municipalismo: a gestão do território amazônico, 2007. Disponível

em:

http://www.nilsonfraga.com.br/anais/SANTOS_Jorge_Paulo_Pereira_dos.pdf.

SANTOS, Julio Cesar Ferreira. As questões de limites interestaduais do Brasil: transição política e instabilidade do território nacional na Primeira República (18891930). Scripta Nova. Revista electrónica de geografía y ciencias sociales. Barcelona: Universidad de Barcelona, 1 de agosto de 2006, vol. X, núm. 218 (17).

SILVA, Andréia Ferreira da. Federalismo, descentralização, municipalização e direito à educação básica no Brasil. 2009. Disponível em: <http://www.anpae.org.br/congressos_antigos/simposio2009/33.pdf>.

SOARES, Márcia Miranda e LOURENÇO, Luiz Cláudio. A representação política dos estados na federação brasileira. Revista Brasileira de Ciências Sociais, vol.19 no 56, São Paulo, outubro de 2004.

SOUZA, Carlos Augusto da S. e BENTES, Elizabeth dos Santos (2010) Redivisão territorial no estado do Pará: Impactos econômicos e interesses políticos. Belém: UNAMA, (Relatório de Pesquisa), 2010.

SOUZA, Carlos Augusto da S. Geografia eleitoral e padrões de competição política no estado do Pará. Tese (Doutorado em Ciência Política). Rio de Janeiro: IUPERJ. 2006.

VIEGAS, Nilza Gonçalves. A colonização portuguesa no Maranhão. Disponível em: http://eduardorodriguesbrito.blogspot.com/2010/06/espaco-maranhao.html.

Recebido em: 28/08/2017

Aprovado em: 10/05/2018 